\title{
Findings in the Distal Colorectum are not associated with Proximal
}

\section{Advanced Serrated Lesions}

Charles J. Kahi, MD, MSCR ${ }^{1,2}$, Krishna C. Vemulapalli, MBBS, MPH ${ }^{1}$, Dale C. Snover, MD ${ }^{3}$, Khaled H. Abdel Jawad, MD ${ }^{4}$, Oscar W. Cummings, MD ${ }^{5}$, Douglas K. Rex, MD ${ }^{1}$

1 Indiana University School of Medicine, Department of Medicine, Division of Gastroenterology and Hepatology, Indianapolis, Indiana

2 Richard L. Roudebush VA Medical Center, Indianapolis, Indiana

3 Department of Pathology, Fairview Southdale Hospital, Edina, Minnesota

4 Indiana University School of Medicine, Department of Medicine

5 Indiana University School of Medicine, Department of Pathology

This work was entirely funded by a gift from Scott and Kay Schurz of Bloomington, Indiana (to DKR)

Author contributions:

CK: Study concept and design, interpretation of data, drafting of manuscript, critical revision of manuscript for important intellectual content

KV: Data acquisition and statistical analysis, critical revision of manuscript for important intellectual content

DS: Data acquisition, critical revision of manuscript for important intellectual content

KAJ: Data acquisition, critical revision of manuscript for important intellectual content

OC: Data acquisition, critical revision of manuscript for important intellectual content

DR: Interpretation of data, critical revision of manuscript for important intellectual content

Abstract word count: 377, Word count: 2,903

\section{Corresponding author:}

Charles J. Kahi, MD, MSCR, FACP, FACG, AGAF

Associate Professor of Clinical Medicine

Indiana University School of Medicine

Gastroenterology Section Chief, Roudebush VA Medical Center

1481 W 10th street, $111 \mathrm{G}$

Indianapolis, IN 46202

Phone: (317) 988-3541

Fax: (317) 988-5313

E-mail: ckahi2@iu.edu

cOl statement: The authors have no conflict of interest relevant to this manuscript to disclose.

This is the author's manuscript of the article published in final edited form as:

Kahi, C. J., Vemulapalli, K. C., Snover, D. C., Abdel Jawad, K. H., Cummings, O. W., \& Rex, D. K. (2015). 1

Findings in the Distal Colorectum Are Not Associated With Proximal Advanced Serrated Lesions. Clinical

Gastroenterology and Hepatology, 13(2), 345-351. http://doi.org/10.1016/j.cgh.2014.07.044 


\section{ABSTRACT}

Background and Aims: Serrated lesions are an important contributor to colorectal cancer (CRC), notably in the proximal colon. Findings in the distal colorectum are markers of advanced proximal adenomatous neoplasia. However, it is not known whether they affect the odds of advanced proximal serrated lesions.

Methods: We performed a retrospective cross-sectional study of data from 1910 patients (59.3 \pm 8.0 years old, $53.8 \%$ female) who underwent an average-risk screening colonoscopy, from August 2005 through April 2012, at Indiana University Hospital and an associated ambulatory surgery center. Colonoscopies were performed by an endoscopist with high rates of detection of adenomas and serrated polyps. Tissue samples of all serrated polyps (hyperplastic, sessile serrated adenoma/polyp [SSA/P] or traditional serrated adenoma) proximal to the sigmoid colon, and serrated polyps $>5 \mathrm{~mm}$ in the rectum or sigmoid colon were reviewed by a gastrointestinal pathologist and reclassified based on World Health Organization criteria. Advanced serrated lesion (ASL) was defined as SSA/P with cytological dysplasia, SSA/P $\geq 10$ $\mathrm{mm}$, or traditional serrated adenoma. Advanced conventional adenomatous neoplasia (ACN) was defined as tubular adenoma $\geq 10 \mathrm{~mm}$, villous histology, high-grade dysplasia, or cancer. The prevalence of proximal ASL and ACN was calculated based on distal colorectal findings. Multivariable logistic regression analysis was performed to determine the age- and sex-adjusted odds of advanced proximal adenomatous and serrated lesions. Secondary analyses were performed to examine the effect of variable ASL definitions.

Results: Fifty-two patients had proximal ASL (2.7\%) and 99 had proximal ACN (5.2\%). Of the 52 patients with proximal ASL, 27 had no distal polyps (52\%). Of the 99 patients with proximal ACN, 40 had no distal polyps (40\%). Age and type of distal adenomas were significantly associated with proximal ACN. There were no significant associations between distal polyp type 
and proximal ASL. In secondary analyses, distal SSA/Ps ( $p=0.008)$, but not distal HPs or conventional adenomas were associated with any proximal SSA/P.

Conclusions: The findings at flexible sigmoidoscopy that traditionally serve as indications for colonoscopy (conventional adenomas), are likely to be ineffective for detection of proximal ASL. This finding, plus the observation that most patients with proximal ASL have no distal polyps, favors screening colonoscopy over sigmoidoscopy, especially in the elderly. The observation that non-advanced distal SSA/Ps are associated with any proximal SSA/P warrants further study.

Keywords: early detection, colon cancer, colonoscopy 
Colorectal cancer (CRC) is preventable and is one of few cancers for which there is considerable evidence that screening is effective and cost-effective ${ }^{1,2}$. Colonoscopy allows the detection and removal of precursor polyps during the same session and is the final common pathway for other screening modalities; these characteristics have contributed to its position as the dominant CRC screening modality in the US. However, colonoscopy requires considerable human and financial resources ${ }^{3,4}$, and the need to balance these constraints with effectiveness has increased interest in strategies where colonoscopy is used selectively after initial testing with one of the other modalities. Sigmoidoscopy is an attractive option because it is more straightforward to perform, is less burdensome, and is associated with lower risk for harm than colonoscopy. Randomized controlled trials ${ }^{5-7}$ and meta-analyses ${ }^{8,9}$ have shown that flexible sigmoidoscopy decreases CRC incidence and mortality, supporting its endorsement by major guideline organizations ${ }^{1}$. Sigmoidoscopy effectively decreases distal CRC incidence and mortality; however, its effect on right-sided CRC depends on the colonoscopy referral strategy in place. The 4 large randomized trials of screening sigmoidoscopy $y^{5-7,10}$ have employed different criteria to refer patients to colonoscopy, but all are based on the premise that the risk of advanced neoplasia in the proximal colon can be predicted according to findings in the distal colon, allowing the adjudication of colonoscopy referrals based on the presence and characteristics of polyps found at sigmoidoscopy ${ }^{11}$. In this context, the term "advanced neoplasia" has been used to refer mainly to lesions on the spectrum of the adenoma-carcinoma sequence, including invasive cancer and advanced adenomas (size $\geq 10 \mathrm{~mm}$ or presence of high-grade dysplasia or significant villous components on histology). Indeed, the studies which supported this approach ${ }^{12-15}$ were performed at a time when it was thought that the great majority of colon cancers arose from precursor conventional adenomas via the chromosomal instability pathway. However, it is now recognized that nearly one-third of CRCs arise through the serrated pathway, which is characterized by mutations in the BRAF gene, high levels of methylation of promoter CpG islands (CIMP-high), and in which the sessile serrated 
adenoma/polyp (SSA/P) is the principle precursor lesion ${ }^{16-18}$. Serrated lesions can be challenging to visualize because of their subtle morphologic characteristics, and are more likely to be overlooked than conventional adenomas ${ }^{19,20}$. These features likely account for the fact that the serrated pathway is a disproportionate contributor to interval CRC (CRC diagnosed relatively soon after colonoscopy). Cancers associated with the serrated pathway tend to occur in the proximal colon and their molecular signature overlaps significantly with interval $\mathrm{CRC}^{21-23}$. The study of serrated lesions has been complicated by evolving definitions and nomenclature, leading to significant inter-observer variability in the histologic differentiation of subtypes of serrated polyps, notably between SSA/P and hyperplastic polyps. The World Health Organization (WHO) has recently updated the classification of serrated colorectal lesions ${ }^{18}$.

While it is recognized that distal colorectal adenomas are a marker of advanced proximal conventional adenomatous neoplasia, it is not known whether the same applies to important proximal serrated lesions, specifically those higher-risk serrated lesions which warrant more intensive surveillance ${ }^{16,24}$. This issue is of relevance for CRC screening strategies which employ sigmoidoscopy as the initial test and refer patients to colonoscopy based on distal findings. Such approaches are based on the assumption that the relevant target proximal colon lesions are predominantly adenoma-based, an assumption which does not take into account serrated lesions and their significant contribution to the pathogenesis of CRC. To help understand whether distal colorectal findings are predictive of advanced serrated lesions in the proximal colon, we analyzed data from a large group of average-risk patients who had undergone screening colonoscopy by an endoscopist with high detection rates of adenomatous and serrated polyps, combined with review of histology by an expert pathologist with specific interest in serrated polyps, using the WHO consensus guidelines. 


\section{METHODS}

This was a cross-sectional study conducted at Indiana University Hospital and an associated ambulatory surgery center in Indianapolis, Indiana. The study was approved by the Institutional Review Board of Indiana University Health. We reviewed a prospectively updated electronic database for all patients $\geq 50$ years old who underwent an average-risk screening colonoscopy between August 2005 and April 2012 by an endoscopist with documented high adenoma and serrated polyp detection rates (DKR). The colonoscopy database contains information regarding patient demographics, and number, location, size, shape and the histopathology of resected polyps. Patients who underwent colonoscopy for any indication other than screening (diagnostic colonoscopy for evaluation of symptoms or occult bleeding, history of inflammatory bowel disease, family history of familial adenomatous polyposis, surveillance colonoscopy after polypectomy or CRC resection), were excluded. The proximal colon was defined as cecum, ascending colon, and transverse colon, and the distal colon as splenic flexure, descending colon, sigmoid colon, and rectum. During the interval in which the colonoscopies were performed, the study colonoscopist did not systematically remove all diminutive hyperplastic appearing lesions from the rectosigmoid colon, particularly in patients who had numerous such lesions.

For the pathology review, we identified all serrated polyps proximal to the sigmoid colon, and serrated polyps $>5 \mathrm{~mm}$ in the rectum or sigmoid colon. Rectosigmoid serrated polyps $\leq 5$ $\mathrm{mm}$ are overwhelmingly hyperplastic and are not considered to have malignant potential ${ }^{16,24}$. Pathology slides were retrieved and reviewed by an experienced GI pathologist (DCS) who was blinded to polyp anatomic location, shape, size, and initial histopathological diagnosis. Serrated polyps were categorized using the WHO classification ${ }^{18}$ into hyperplastic polyps (HP), sessile serrated polyps without (SSA/P) and with cytological dysplasia (SSA/P-CD), and traditional serrated adenomas (TSA). SSA/P was diagnosed if a serrated lesion had at least one crypt 
showing evidence of abnormal proliferation and maturation as evidenced by mature cells at the base of the crypt associated with a dilated, boot or anchor shape and/or excess crypt serration near the base. A diagnosis of HP required that all crypts show normal maturation toward the surface with a normally located basal proliferative zone. For the primary analysis, we targeted serrated lesions which are considered to be at higher risk for progression to cancer, warranting colonoscopic surveillance intervals similar to those of advanced conventional adenomas ${ }^{16,24}$. We refer to these lesions as "advanced serrated lesions" (ASL), grouping SSA/P-CD, SSA/P $\geq$ $10 \mathrm{~mm}$, or TSA. We performed a secondary analysis to determine the odds of any proximal SSA/P (regardless of size or presence of cytological dysplasia) in patients with distal colorectal polyps, compared to patients with no distal polyps. Advanced conventional adenomatous neoplasia $(A C N)$ was defined as tubular adenoma $(T A) \geq 10 \mathrm{~mm}$, villous histology, high-grade dysplasia, or cancer. Patients were divided into six groups based on their most advanced distal colon finding in the following order - ACN, ASL, non-advanced TA, SSA/P<10 mm, HP, and no polyps. There were no patients with synchronous distal ASL and ACN.

\section{Statistical analysis}

Descriptive statistics were used to characterize patient demographic features, and to determine the prevalence of proximal and distal colon polyps stratified by patient sex. The number of patients in whom the most advanced lesion was ACN, and the number of patients in whom the most advanced lesion was ASL, were determined. The prevalence of proximal ASL and ACN based on distal colorectal findings was calculated. Multivariable logistic-regression analysis was performed to determine the age- and sex-adjusted odds of advanced proximal adenomatous and serrated lesions, with patients without distal polyps as the reference group. Based on the overall sample size of 1910 patients, we determined that the study had $80 \%$ power to detect an odds ratio of 2.5 for distal polyp as a predictor of ASL or ACN, using a logistic regression model with age and sex as covariates. 


\section{RESULTS}

The study cohort consisted of 1910 average-risk patients who underwent a screening colonoscopy between August 2005 and April 2012. Most patients (1675/1910, 87.7\%) had no recorded family history of CRC. In the remaining 235, $212(11.1 \%)$ had a first degree relative and $23(1.2 \%)$ had a distant relative with CRC. The mean age was $59.3 \pm 8.0$ years, and 53.8\% were female. The number of patients with at least one conventional adenoma was 914 (47.8\%), and the number of patients with at least one serrated lesion (includes HP, SSA/P, and TSA) was 688 (36.0\%). The corresponding detection rates for advanced conventional adenoma and advanced serrated lesions were $7.4 \%$ and $3.0 \%$, respectively. Overall, distal, and proximal colon findings and patient characteristics are shown in Table 1. Five cancers were diagnosed, 3 in the proximal colon and 2 in the distal colon. There were 52 patients (2.8\%) with proximal ASL, and 99 (5.1\%) with proximal ACN (one patient had both proximal ASL and ACN). Table 2 lists the subcategories of serrated lesions in patients with proximal and distal ASL. Among the 99 patients with proximal $A C N, 61$ had at least one $T A \geq 10 \mathrm{~mm}, 40$ had at least one adenoma with villous histology, 9 had at least one adenoma with high-grade dysplasia, and 3 had invasive cancer.

Of 52 patients with proximal ASL, 27 (52\%) had no distal polyps removed; of 99 patients with proximal ACN, 40 (40\%) had no distal polyps. The age- and sex- adjusted odds of advanced proximal adenomatous and serrated lesions according to distal findings are detailed in Table 3. Age and type of distal neoplasia (except non-advanced serrated lesions) were associated with proximal ACN. Conversely, only patient age was significantly associated with proximal ASL. There were no significant associations between distal polyps and proximal ASL.In secondary analyses (Table 4), presence of a distal SSA/P was the lone factor associated with a proximal SSA/P. There were no significant associations with either age or gender. 


\section{DISCUSSION}

In this study, average-risk patients 50 years of age or older with distal colorectal polyps were no more likely to harbor advanced serrated lesions in the proximal colon than patients without distal colorectal polyps. In addition, more than half of patients with advanced proximal serrated lesions had no polyps in the distal colon.

Our findings extend and update those studies which addressed similar questions, with focus on proximal advanced conventional adenomas. Imperiale et al ${ }^{12}$ reported increased risk of proximal advanced adenomatous neoplasia with increasing age, male sex, presence of distal hyperplastic polyps, distal tubular adenomas, and distal advanced polyps. An updated and expanded analysis of 10,124 patients aged 50 years or older who underwent colonoscopy found that age, male sex, and distal adenomas (but not distal hyperplastic polyps) were associated with increased risk of proximal advanced adenomatous neoplasia ${ }^{25}$. Consistent with these findings and reports by Levin et al. ${ }^{14}$, Schoen et al. ${ }^{15}$, and Wallace et al. ${ }^{13}$, we found similar relationships between advanced proximal adenomatous neoplasia, and patient age and distal colorectal findings. Additionally, $40 \%$ of patients with proximal ACN in our cohort had no distal colorectal findings, which is comparable to previous reports ${ }^{12}$. However, previous studies did not evaluate the association with proximal advanced serrated lesions. We found only patient age to be significantly associated with proximal ASL, while sex and type of distal colorectal neoplasia were not. The proportion of patients with proximal ASL and no distal colorectal polyps was 52\%, exceeding the proportion of patients with proximal ACN and no distal colorectal polyps.

These findings are relevant for CRC screening strategies which employ sigmoidoscopy as a "gateway" test, and triage patients to colonoscopy based on findings at sigmoidoscopy. Distal colorectal findings are associated with the risk of proximal advanced adenomatous neoplasia and can be used to tailor screening recommendations and colonoscopy referrals 
based on evidence-based estimates of the risk of proximal $\mathrm{ACN}^{11}$. However, the observation that patients with distal colorectal polyps are no more likely to harbor advanced serrated lesions in the proximal colon than patients without distal colorectal polyps is concerning. For example, a patient with no polyps at sigmoidoscopy who is not referred for a follow-up colonoscopy based exclusively on the estimated risk of advanced $\mathrm{ACN}$, could be harboring significant serrated lesions in the proximal colon which would go undetected. The implications of the lack of association between distal polyps and proximal ASL risk on the relative effectiveness of endoscopic screening strategies are not clear, but may be substantial given the disproportionate contribution of the serrated pathway to proximal and interval CRC. The observation that increasing age was associated with the risk of proximal ASL warrants additional comment. Epidemiologic studies have shown a rightward shift in the distribution of CRC which may be related to population aging, and proximal colon cancer is associated with molecular features which increase with age and are linked to the serrated pathway (such as methylation and microsatellite instability $)^{26,27}$. Thus, screening colonoscopy may be more appropriate than a sigmoidoscopy-first approach in older age groups from the standpoint of detection of advanced proximal serrated lesions. Previous work has shown that tailoring CRC screening by quantifying the risk of proximal $\mathrm{ACN}$ is feasible, and allows the identification of low risk groups (such as younger women) who could undergo sigmoidoscopy instead of colonoscopy ${ }^{25}$. Our study sample size did not allow us to conduct similar subgroup analyses. Future studies with larger sample sizes should incorporate advanced serrated lesions as a relevant CRC prevention target, as this would help further refine current tailoring and risk-stratification strategies, notably by identifying patient groups at lower risk for proximal ASL.

An important feature of our study is the combination of the endoscopic findings of colonoscopies performed by a high level detector, with a review of serrated polyps by an experienced pathologist using the most recent consensus guidelines. This approach is 
advantageous for 2 main reasons: First, previous studies reporting prevalence rates of serrated lesions in fact reflected the mean detection rates of endoscopists with highly variable detection of serrated lesions. Restricting the analysis to a single high-level detector allows the derivation of more precise estimates of the relative risks of proximal advanced serrated and adenomatous neoplasms based on distal colorectal findings in the same cohort of average-risk patients.

Second, the histopathologic review of serrated polyps by a single experienced pathologist using the most recent WHO consensus guidelines overcomes the issue of variable pathological criteria to define SSA/P.

Our study has limitations which require additional discussion. First, the definition we used for advanced serrated lesions is empiric, and is based on consensus guidelines which have identified SSA/P with cytological dysplasia, SSA/P $\geq 10 \mathrm{~mm}$, and TSA as equivalent to high-risk conventional adenomas which require more intensive post-polypectomy surveillance ${ }^{24}$. The evidence supporting the concept of advanced serrated lesions is less robust than that for advanced conventional adenomatous neoplasia, and awaits further data from well-designed longitudinal studies. However, using proximal SSA/P regardless of size or presence of cytological dysplasia as the relevant target lesion, also showed no significant association between distal findings and proximal SSA/P, with the exception of distal SSA/P group. In this regard, the study colonoscopist did not systematically remove all diminutive hyperplastic appearing polyps from the rectosigmoid colon. Thus, we could have missed a significant association between distal colon hyperplastic and proximal ASL, or between distal hyperplastic polyps and any proximal SSA/P, or between distal SSA/P and proximal serrated endpoints, and any missed associations of distal and proximal serrated polyps could have resulted from either an insufficient sample size or incomplete clearing of distal colon hyperplastic appearing polyps. We recommend additional study of the association of distal colon and proximal serrated lesions. 
Second, although the overall sample size was large, the number of proximal ASL and ACN "events" was relatively small, precluding certain subgroup analyses; for example, we could not determine the odds of proximal ACN or ASL for the subgroup with distal ASL with precision, because the latter included only 7 patients. However, we do not believe that the proximal ASL prevalence in our study to be a limitation: the proximal $A C N$ prevalence rates are comparable to those reported in other similar studies ${ }^{12}$, and our proximal ASL rates are thus likely more reflective of the actual prevalence of these lesions in average-risk cohorts.

Third, as with previous studies, our study's cross-sectional design and the database on which it is based limited our ability to account for relevant clinical information such as bodymass index, tobacco use, and use of NSAIDs, which may influence individual patients' risk for CRC. Finally, distal colorectal findings at sigmoidoscopy were estimated based on findings at colonoscopy. The depth of insertion at sigmoidoscopy may vary in clinical practice; however, we considered sigmoidoscopy to be complete and the splenic flexure reached in all instances, an assumption which is similar to previous studies.

In summary, we found that distal colon adenomas, which are the clinically accepted indicators for colonoscopy when detected at sigmoidoscopy, were not associated with advanced proximal colon serrated lesions. A policy of referral for colonoscopy only for distal colon conventional adenomas detected by screening flexible sigmoidoscopy will likely fail to detect important proximal serrated lesions. Further, more than half of patients with advanced proximal serrated lesions had no polyps in the distal colon. Taken together, to the extent that detection of proximal advanced serrated lesions is important to colon cancer prevention, our findings favor screening colonoscopy over sigmoidoscopy, especially with increasing age. Distal colon nonadvanced serrated lesions as a class were associated with any proximal colon SSA/P. This suggests that distal colon hyperplastic polyps (or distal serrated lesions collectively), traditionally considered to have no importance when detected during screening flexible sigmoidoscopy, may 
be a signal for proximal colon SSA/P. Additional evaluation of this potentially important association, to determine which (if any) subgroups of distal serrated lesions are associated with proximal serrated findings warrants further evaluation. 
Table 1 Distribution of colon findings according to the most advanced lesion

\begin{tabular}{|c|c|c|c|c|c|c|c|c|c|}
\hline \multirow[t]{2}{*}{ Most advanced finding } & \multicolumn{3}{|c|}{ Proximal Colon } & \multicolumn{3}{|c|}{ Distal Colon } & \multicolumn{3}{|c|}{ Anywhere in the colon } \\
\hline & $\mathrm{N}(\%)$ & $\begin{array}{l}\text { Age } \\
\text { (SD) }\end{array}$ & $\begin{array}{l}\text { Sex, } \\
\text { male } \\
(\%)\end{array}$ & $\mathrm{N}(\%)$ & $\begin{array}{l}\text { Age } \\
\text { (SD) }\end{array}$ & $\begin{array}{c}\text { Sex, } \\
\text { male } \\
(\%)\end{array}$ & $\mathrm{N}(\%)$ & $\begin{array}{l}\text { Age } \\
\text { (SD) }\end{array}$ & $\begin{array}{c}\text { Sex, } \\
\text { male } \\
(\%)\end{array}$ \\
\hline No polyps & $\begin{array}{l}956 \\
(50.1)\end{array}$ & $\begin{array}{l}57.9 \\
(7.2)\end{array}$ & $\begin{array}{l}390 \\
(40.8)\end{array}$ & $\begin{array}{l}1134 \\
(59.4)\end{array}$ & $\begin{array}{l}59.1 \\
(7.8)\end{array}$ & $\begin{array}{l}494 \\
(43.6)\end{array}$ & $\begin{array}{l}646 \\
(33.8)\end{array}$ & $\begin{array}{l}58.1 \\
(7.3)\end{array}$ & $\begin{array}{l}253 \\
(39.2)\end{array}$ \\
\hline$H P$ & $\begin{array}{l}125 \\
(6.5)\end{array}$ & $\begin{array}{l}58.3 \\
(7.3)\end{array}$ & $\begin{array}{l}51 \\
(40.8)\end{array}$ & $\begin{array}{l}330 \\
(17.3)\end{array}$ & $\begin{array}{l}58.4 \\
(7.6)\end{array}$ & $\begin{array}{l}145 \\
(43.9)\end{array}$ & $\begin{array}{l}264 \\
(13.8)\end{array}$ & $\begin{array}{l}57.3 \\
(6.8)\end{array}$ & $103(39)$ \\
\hline $\begin{array}{l}S S A / P<10 m m \text { with or without } \\
H P\end{array}$ & $55(2.9)$ & $\begin{array}{l}57.2 \\
(7.3)\end{array}$ & $\begin{array}{l}23 \\
(41.8)\end{array}$ & $\begin{array}{l}16 \\
(0.8)\end{array}$ & $\begin{array}{l}58.6 \\
(7.9)\end{array}$ & $8(50)$ & $\begin{array}{l}60 \\
(3.1)\end{array}$ & $\begin{array}{l}57.1 \\
(7.5)\end{array}$ & $\begin{array}{l}26 \\
(43.3)\end{array}$ \\
\hline $\begin{array}{l}\text { Non-advanced adenoma with } \\
\text { or without non-advanced } \\
\text { serrated }(S S A / P<10 m m+H P) \\
\text { neoplasia }\end{array}$ & $\begin{array}{l}624 \\
(32.7)\end{array}$ & $\begin{array}{l}60.9 \\
(8.1)\end{array}$ & $\begin{array}{l}344 \\
(55.1)\end{array}$ & $\begin{array}{l}362 \\
(19)\end{array}$ & $\begin{array}{l}60.7 \\
(8.5)\end{array}$ & $\begin{array}{l}200 \\
(55.2)\end{array}$ & $\begin{array}{l}746 \\
(39.1)\end{array}$ & $\begin{array}{l}60.4 \\
(8.1)\end{array}$ & $403(54)$ \\
\hline$A S L(S S A / P>=10, S S A / P-C D, T S A)$ & $51(2.7)$ & $\begin{array}{l}61.8 \\
(9.1)\end{array}$ & $\begin{array}{l}18 \\
(35.3)\end{array}$ & $7(0.4)$ & $\begin{array}{l}60 \\
(9.6)\end{array}$ & $\begin{array}{l}5 \\
(71.4)\end{array}$ & $\begin{array}{l}53 \\
(2.8)\end{array}$ & $\begin{array}{l}61.5 \\
(9.2)\end{array}$ & $\begin{array}{l}21 \\
(39.6)\end{array}$ \\
\hline$A C N$ & $98(5.1)$ & $\begin{array}{l}63.8 \\
(9.8)\end{array}$ & $\begin{array}{l}56 \\
(57.1)\end{array}$ & $\begin{array}{l}61 \\
(3.2)\end{array}$ & $\begin{array}{l}59.7 \\
(7.9)\end{array}$ & $\begin{array}{l}31 \\
(50.8)\end{array}$ & $\begin{array}{l}136 \\
(7.1)\end{array}$ & $\begin{array}{l}62.2 \\
(9.5)\end{array}$ & $\begin{array}{l}75 \\
(55.1)\end{array}$ \\
\hline$A S L+A C N$ & $1(0.1)$ & 68 & $1(100)$ & & & & $5(0.3)$ & $\begin{array}{l}62 \\
(6.9)\end{array}$ & $2(40)$ \\
\hline
\end{tabular}

ACN - Advanced conventional neoplasia

ASL - Advanced serrated lesion

$\mathrm{HP}$ - Hyperplastic polyp

SSA/P - Sessile serrated adenoma/polyp

SSA/P-CD - Sessile serrated adenoma/polyp with cytological dysplasia

TSA - Traditional serrated adenoma 
Table 2 Subcategories of advanced serrated lesions

\begin{tabular}{|c|c|}
\hline $\begin{array}{l}52 \text { patients with proximal } \mathrm{ASL}(\mathrm{s}) \\
\text { (only proximal lesions) }\end{array}$ & $\begin{array}{l}34 \text { patients had } 1 \mathrm{SSA} / \mathrm{P}>=10 \mathrm{~mm} \text { each } \\
1 \text { patient had } 1 \mathrm{SSA} / \mathrm{P}-\mathrm{CD}>=10 \mathrm{~mm} \\
7 \text { patients had } 1 \mathrm{SSA} / \mathrm{P}-\mathrm{CD} \text { each } \\
1 \text { patient had } 1 \mathrm{TSA}-\mathrm{CD} \\
1 \text { patient had } 2 \mathrm{SSA} / \mathrm{P}-\mathrm{CDs} \\
4 \text { patients had } 2 \mathrm{SSA} / \mathrm{Ps} \text { each greater than } 10 \mathrm{~mm} \\
1 \text { patient had } 1 \mathrm{SSA} / \mathrm{P}>=10 \mathrm{~mm} \text { and } 1 \mathrm{SSA} / \mathrm{P}-\mathrm{CD} \\
1 \text { patient had } 1 \mathrm{SSA} / \mathrm{P}>=10 \mathrm{~mm} \text { and } 1 \mathrm{TSA} \\
1 \text { patient had } 1 \mathrm{SSA} / \mathrm{P}-\mathrm{CD} \text { and } 1 \mathrm{TSA}-\mathrm{CD} \\
1 \text { patient had } 3 \mathrm{SSA} / \mathrm{Ps} \text { all greater than } 10 \mathrm{~mm}\end{array}$ \\
\hline $\begin{array}{l}7 \text { patients with distal ASL(s) } \\
\text { (only distal lesions) }\end{array}$ & $\begin{array}{l}3 \text { patients with } 1 \mathrm{SSA} / \mathrm{P}>=10 \mathrm{~mm} \text { each } \\
1 \text { patient with } 1 \mathrm{TSA}-\mathrm{CD} \\
1 \text { patient with } 1 \mathrm{TSA} \\
1 \text { patient with } 1 \mathrm{SSA} / \mathrm{P}-\mathrm{CD}>=10 \mathrm{~mm} \\
1 \text { patient with } 2 \mathrm{TSA}-\mathrm{CDs}\end{array}$ \\
\hline
\end{tabular}

ASL - Advanced serrated lesion

HP - Hyperplastic polyp

SSA/P - Sessile serrated adenoma/polyp

SSA/P-CD - Sessile serrated adenoma/polyp with cytological dysplasia

TSA - Traditional serrated adenoma

TSA-CD - Traditional serrated adenoma with cytological dysplasia 
Table 3 Odds of proximal advanced conventional neoplasia and proximal advanced serrated lesions based on distal findings $\dagger$

\begin{tabular}{|c|c|c|c|c|c|c|c|}
\hline Risk factor & $\mathrm{N}$ & $\begin{array}{l}\text { proximal } \\
\text { ACN, } \\
\mathrm{N}(\%)\end{array}$ & OR $(95 \% \mathrm{Cl}) *$ & $\begin{array}{l}p- \\
\text { value }\end{array}$ & $\begin{array}{l}\text { proximal } \\
\text { ASL, } \\
\mathrm{N}(\%)\end{array}$ & OR $(95 \% \mathrm{Cl}) *$ & $\begin{array}{l}\mathrm{p}- \\
\text { value }\end{array}$ \\
\hline \multicolumn{8}{|l|}{ Distal colon finding } \\
\hline No polyps & 1134 & $40(3.5)$ & 1 (reference) & & $27(2.4)$ & 1 (reference) & \\
\hline$H P$ & 330 & $5(1.5)$ & $0.44(0.17-1.13)$ & 0.09 & $9(2.7)$ & $1.18(0.55-2.54)$ & 0.67 \\
\hline$S S A / P<10 \mathrm{~mm}$ with or without $H P$ & 16 & 0 & - & 1.0 & $1(6.3)$ & $2.95(0.37-23.34)$ & 0.31 \\
\hline without non-advanced serrated & & & & & & & \\
\hline lesions $(S S A / p+H P)$ & 362 & $33(9.1)$ & $2.38(1.46-3.87)$ & $<0.01$ & $11(3)$ & $1.28(0.62-2.62)$ & 0.5 \\
\hline$A S L$ & 7 & $2(28.6)$ & $10.22(1.85-56.57)$ & $<0.01$ & $1(14.3)$ & $7.45(0.83-66.69)$ & 0.07 \\
\hline$A C N$ & 60 & $18(30)$ & $12.18(6.33-23.43)$ & $<0.01$ & $2(3.3)$ & $1.43(0.33-6.2)$ & 0.63 \\
\hline \multicolumn{3}{|l|}{ Age } & $1.07(1.04-1.09)$ & $<0.01$ & - & $1.04(1.01-1.07)$ & 0.03 \\
\hline \multicolumn{3}{|l|}{ Male sex } & $1.47(0.95-2.25)$ & 0.08 & - & $0.6(0.33-1.08)$ & 0.09 \\
\hline
\end{tabular}

† 1 patient with synchronous proximal ACN and proximal ASL excluded

* OR adjusted for age and sex, group with no neoplasia is the reference group

ACN - Advanced conventional neoplasia

ASL - Advanced serrated lesion

$\mathrm{HP}$ - Hyperplastic polyp

SSA/P - Sessile serrated adenoma/polyp 
Table 4 Odds of proximal sessile serrated adenoma/polyps based on distal findings

\begin{tabular}{|l|l|l|l|l|}
\hline Risk factor & $\mathrm{N}$ & $\begin{array}{l}\text { Any proximal } \\
\text { SSA/P, N (\%) }\end{array}$ & OR (95\% CI)* & P-value \\
\hline $\begin{array}{l}\text { Distal colon finding } \\
\quad \text { No polyps }\end{array}$ & 1134 & $75(6.6)$ & 1 (reference) & - \\
$\quad$ HP & 330 & $30(9.1)$ & $1.42(0.91-2.21)$ & 0.12 \\
$\quad$ SSA/P<10mm with or without HP & 16 & $4(25)$ & $4.74(1.5-15.05)$ & $<0.01$ \\
$\quad$ Non-advanced adenoma with or without non-advanced & & & & \\
serrated lesions (SSA/P+HP) & 362 & $21(5.8)$ & $0.87(0.53-1.44)$ & 0.58 \\
$\quad$ ASL & 61 & $1(14.3)$ & $2.38(0.28-20.08)$ & 0.43 \\
$\quad$ ACN & $7(11.5)$ & $1.83(0.81-4.17)$ & 0.15 \\
\hline Age & & $1(0.98-1.03)$ & 0.7 \\
\hline Male sex & & $0.95(0.67-1.34)$ & 0.76 \\
\hline
\end{tabular}

* OR adjusted for age and sex, group with no neoplasia is the reference group

ACN - Advanced conventional neoplasia

ASL - Advanced serrated lesion

HP - Hyperplastic polyp

SSA/P - Sessile serrated adenoma/polyp 


\section{References}

1. Levin B, Lieberman DA, McFarland B, et al. Screening and surveillance for the early detection of colorectal cancer and adenomatous polyps, 2008: a joint guideline from the American Cancer Society, the US Multi-Society Task Force on Colorectal Cancer, and the American College of Radiology. Gastroenterology 2008;134:1570-95.

2. Pignone M, Saha S, Hoerger T, Mandelblatt J. Cost-effectiveness analyses of colorectal cancer screening: a systematic review for the U.S. Preventive Services Task Force. Ann Intern Med 2002;137:96104.

3. Seeff LC, Richards TB, Shapiro JA, et al. How many endoscopies are performed for colorectal cancer screening? Results from CDC's survey of endoscopic capacity. Gastroenterology 2004;127:1670-7. 4. Seeff LC, Manninen DL, Dong FB, et al. Is there endoscopic capacity to provide colorectal cancer screening to the unscreened population in the United States? Gastroenterology 2004;127:1661-9.

5. Atkin WS, Edwards R, Kralj-Hans I, et al. Once-only flexible sigmoidoscopy screening in prevention of colorectal cancer: a multicentre randomised controlled trial. Lancet 2010;375:1624-33.

6. Schoen RE, Pinsky PF, Weissfeld JL, et al. Colorectal-cancer incidence and mortality with screening flexible sigmoidoscopy. N Engl J Med 2012;366:2345-57.

7. Segnan N, Armaroli P, Bonelli L, et al. Once-only sigmoidoscopy in colorectal cancer screening: follow-up findings of the Italian Randomized Controlled Trial--SCORE. J Natl Cancer Inst 2011;103:131022.

8. Elmunzer BJ, Hayward RA, Schoenfeld PS, Saini SD, Deshpande A, Waljee AK. Effect of flexible sigmoidoscopy-based screening on incidence and mortality of colorectal cancer: a systematic review and meta-analysis of randomized controlled trials. PLoS medicine 2012;9:e1001352.

9. Littlejohn C, Hilton S, Macfarlane GJ, Phull P. Systematic review and meta-analysis of the evidence for flexible sigmoidoscopy as a screening method for the prevention of colorectal cancer. $\mathrm{Br} J$ Surg 2012;99:1488-500.

10. Hoff G, Grotmol T, Skovlund E, Bretthauer M, Norwegian Colorectal Cancer Prevention Study G. Risk of colorectal cancer seven years after flexible sigmoidoscopy screening: randomised controlled trial. Bmj 2009;338:b1846.

11. Castells A, Bessa X, Quintero E, et al. Risk of advanced proximal neoplasms according to distal colorectal findings: comparison of sigmoidoscopy-based strategies. J Natl Cancer Inst 2013;105:878-86.

12. Imperiale TF, Wagner DR, Lin CY, Larkin GN, Rogge JD, Ransohoff DF. Risk of advanced proximal neoplasms in asymptomatic adults according to the distal colorectal findings. $\mathrm{N}$ Engl J Med 2000;343:169-74.

13. Wallace MB, Kemp JA, Trnka YM, Donovan JM, Farraye FA. Is colonoscopy indicated for small adenomas found by screening flexible sigmoidoscopy? Ann Intern Med 1998;129:273-8.

14. Levin TR, Palitz A, Grossman S, et al. Predicting advanced proximal colonic neoplasia with screening sigmoidoscopy. JAMA 1999;281:1611-7.

15. Schoen RE, Corle D, Cranston L, et al. Is colonoscopy needed for the nonadvanced adenoma found on sigmoidoscopy? The Polyp Prevention Trial. Gastroenterology 1998;115:533-41.

16. Rex DK, Ahnen DJ, Baron JA, et al. Serrated lesions of the colorectum: review and recommendations from an expert panel. Am J Gastroenterol 2012;107:1315-29; quiz 4, 30.

17. Snover DC. Update on the serrated pathway to colorectal carcinoma. Hum Pathol 2011;42:1-10.

18. Snover DC AD, Burt RW, Odze RD. Serrated polyps of the colon and rectum and serrated ("hyperplastic") polyposis. In: Bozman FT CF, Hruban RH, Theise N, editors., ed. WHO classification of tumours of the digestive system. Berlin: Springer-Verlag; 2010. 
19. Kahi CJ, Hewett DG, Norton DL, Eckert GJ, Rex DK. Prevalence and variable detection of proximal colon serrated polyps during screening colonoscopy. Clin Gastroenterol Hepatol 2011;9:42-6.

20. Hetzel JT, Huang CS, Coukos JA, et al. Variation in the detection of serrated polyps in an average risk colorectal cancer screening cohort. Am J Gastroenterol 2010;105:2656-64.

21. Arain MA, Sawhney M, Sheikh S, et al. CIMP status of interval colon cancers: another piece to the puzzle. Am J Gastroenterol;105:1189-95.

22. Nishihara R, Wu K, Lochhead P, et al. Long-term colorectal-cancer incidence and mortality after lower endoscopy. N Engl J Med 2013;369:1095-105.

23. Sawhney MS, Farrar WD, Gudiseva S, et al. Microsatellite instability in interval colon cancers. Gastroenterology 2006;131:1700-5.

24. Lieberman DA, Rex DK, Winawer SJ, et al. Guidelines for colonoscopy surveillance after screening and polypectomy: a consensus update by the US Multi-Society Task Force on Colorectal Cancer. Gastroenterology 2012;143:844-57.

25. Imperiale TF, Glowinski EA, Lin-Cooper C, Ransohoff DF. Tailoring colorectal cancer screening by considering risk of advanced proximal neoplasia. Am J Med 2012;125:1181-7.

26. Cucino C, Buchner AM, Sonnenberg A. Continued rightward shift of colorectal cancer. Dis Colon Rectum 2002;45:1035-40.

27. Miyakura $\mathrm{Y}$, Sugano K, Konishi F, et al. Extensive methylation of hMLH1 promoter region predominates in proximal colon cancer with microsatellite instability. Gastroenterology 2001;121:13009. 